\title{
Vida y obra del pintor malagueño Horacio Lengo Martínez de Baños (1834-1890)
}

\author{
ALMARZA BURBANO, María Elisa \\ Universidad de Málaga, Málaga, 2019 \\ ISBN: 978-84-17449-88-9
}

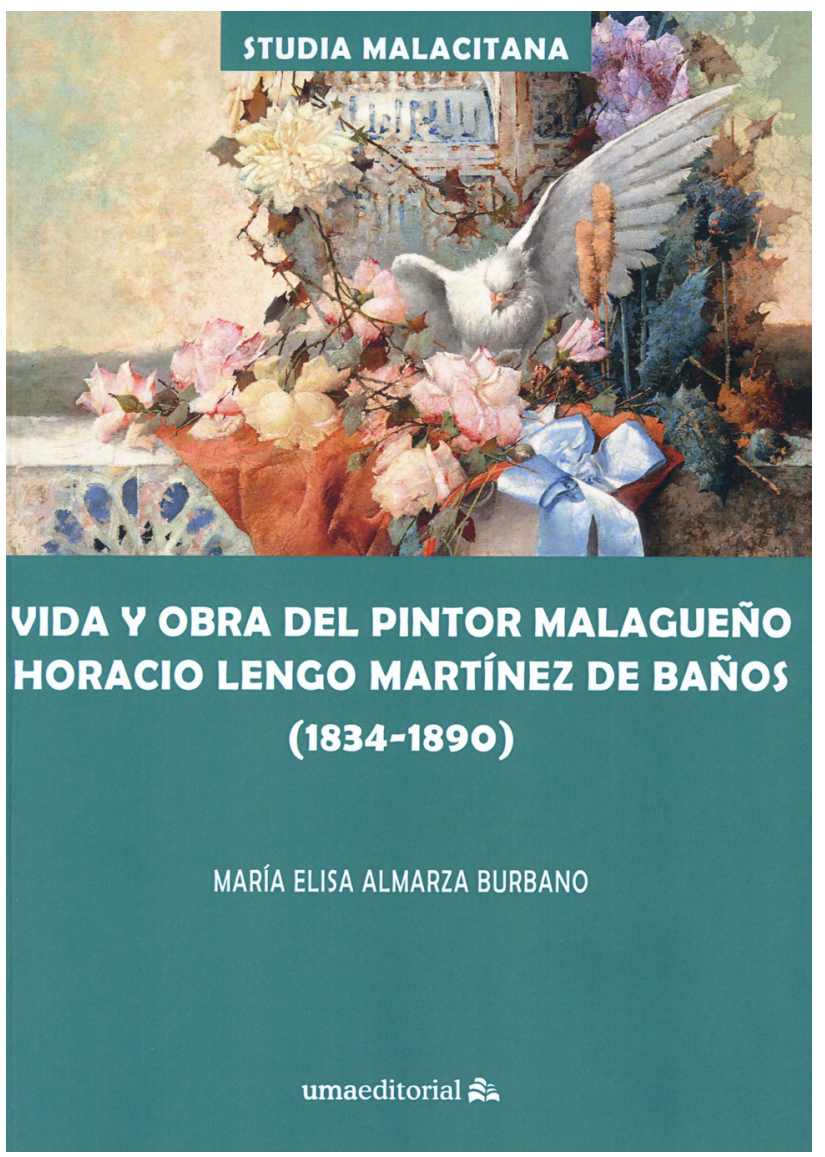

Que Málaga constituyó un prolífico núcleo de producción pictórica durante el siglo XIX y el primer tercio del XX es algo conocido y constatable, tan solo basta visitar los fondos del recientemente reabierto Museo de Málaga. La bonanza económica propiciada por el desarrollo comercial primero, e industrial después, enriqueció a una burguesía que demandaba arte como expresión genuina de su status social y refinamiento cultural. La calidad e interés de los artistas que integraron esta actividad pictórica han venido siendo objeto de diferentes estudios e investigaciones, inicialmente en for- ma de análisis general que aportaron una visión global del mismo, y, posteriormente, en forma de monografías dedicadas a los pintores más destacados, muchas de ellas con origen en trabajos académicos de posgrado desarrollados en el seno de la universidad malagueña.

Pese al éxito y el reconocimiento social que disfrutó, y tener dedicada en Málaga, su ciudad (nació en Torremolinos), una importante calle, Horacio Lengo carecía de una investigación monográfica que arrojara luz sobre su figura y lo situara en el contexto artístico y social de su época. Este es el hueco que vino a completar el documentado libro del que es autora la investigadora Elisa Almarza.

Salvo en las circunstancias que pusieron fin a su vida, Lengo no responde al prototipo de artista romántico que emerge desde el anonimato para ser descubierto y obtener el éxito. Horacio Lengo era miembro de la burguesía local, emparentado y relacionado con destacados miembros de la política y profesionales liberales de su época. Incluso tuvo incursiones en la política con aspiraciones a ser elegido diputado provincial, gracias a su amistad con el influyente político antequerano Romero Robledo. Ingresó como funcionario en la Administración de Aduanas y pasó por distintos destinos. Una situación resuelta en lo económico y lo social que le habría permitido disfrutar de una vida fácil y carente de preocupaciones.

Lengo tenía, eso sí, inquietudes artísticas -como otros tantos miembros de la burguesía que la cultivaron como un hobby- con la salvedad que desde muy joven demostró poseer amplias aptitudes para el dibujo. Fue precisamente en su primer destino como funcionario fuera de Málaga donde, fascinado por la intensa vida cultural de Cádiz, conoció al que sería su primer maestro, el pintor Serafín Martínez del Rincón, con quien desarrolló una intensa amistad.

Cosechados los primeros éxitos y tras regresar a Málaga para hacerse cargo del negocio familiar, concibe la irresistible pasión de dedicarse profesionalmente a la pintura, y 
a una edad madura, ya con 40 años, se marcha a París para adquirir nuevos conocimientos que lo enfilaran hacia el anhelado éxito. No fue la suya una estancia bohemia, sino cómoda, pues los tres años que pasó con su segundo maestro, Leon Bonnat, los sufragó con una herencia familiar. Hemos de aducir en favor de Lengo su intensa actividad como crítico de arte, periodista y escritor. Una formación humanística fuera del ámbito cronológico del Renacimiento que sin duda le ayudó a su progresión social -que no económica- a su regreso a Málaga, primero, y Madrid después.

Para entonces ya se dedicaba profesionalmente a la pintura y como pintor aparecía empadronado. Sus éxitos se traducían en su presencia en exposiciones nacionales e internacionales y la adquisición de obra suya por parte del ayuntamiento malagueño, la diputación de Cádiz, el Museo del Prado, la Casa Real y, sobre todo, una clase acomodada que reclamaba con fruición aquellos temas que le hicieron famoso. En el ámbito local, su cuadro La moraga, es, quizás, su obra más conocida y emblemática por sus connotaciones enraizadas en la tradición local y el acierto con el que vino a retratar a los tipos populares que protagonizan el cuadro.

Oficialmente fue la amenaza de una enfermedad ocular que le privaría de desempeñar su gran pasión por la pintura la que lo llevó a quitarse la vida a la temprana edad de 56 años; aunque la crítica posterior no ha dejado de especular si su almibarada producción pictórica, tan del gusto de la burguesía coleccionista de la época, colmaba realmente sus altas aspiraciones artísticas al margen del éxito comercial.

$Y$ es que aquí reside realmente su tragedia personal: para mantener su acomodado nivel de vida, al que siempre estuvo acostumbrado, se veía obligado a pintar sin cesar. Especialmente sus caprichos y naturalezas muertas surgían con profusión de su taller madrileño garantizando su subsistencia. Pero nunca ejerció la temática histórica que por entonces otorgaba prestigio a los pintores de su época. Tipos costumbristas, animales y personajes literarios constituyeron el grueso de su producción. Todo coleccionista que se jactara aspiraba a disponer de uno de sus caprichos, en los que los palomos asumían roles y actitudes cuasi humanas, representando amantes y personajes literarios. Pero hay que reconocer que lo que hizo, lo hizo con acierto y un induda- ble manejo técnico con los que desarrolló unas capacidades que pronto resultaron claramente identificables con su personalidad artística.

La suya no fue una pintura social o reivindicativa, sino amable y dulzona. Fue, por el contrario, muy versátil en cuanto a su producción, en la que mediante la técnica al óleo -aunque también con la acuarela- produjo paisajes, un cartel, dibujos y particularmente afortunados retratos, aptitud esta que había pasado desapercibida ante el éxito de sus caprichos y que esta monografía se ha encargado de reivindicar. Y del lápiz, la plumilla y la tinta china emergieron sus caricaturas, concebidas con acierto fisonómico, humor y ausencia de ácida crítica. Sin duda realizó varios álbumes aunque hoy solo se conserve el del Casino Gaditano, todo un retrato de la época. Con esta técnica, en la que merece un indudable reconocimiento, nos permitió conocer a destacados personajes de su época.

Su temprana muerte magnificó su figura y casi la sumió en la leyenda. Datos imprecisos o erróneos proliferaron en la literatura artística hasta que un minucioso seguimiento documental y de las fuentes hemerográficas de la época ha permitido situar a Horacio Lengo en su justo lugar. Como algún crítico de su época se encargó de constatar, Lengo, ni mereció totalmente aquel encumbramiento, ni tampoco su posterior olvido. La localización y estudio de su producción, muy dispersa geográficamente por su papel en el mercado del arte debido a la alta demanda, han permitido emitir un certero juicio crítico hacia su pintura.

Una de las aportaciones destacables de este libro es la continua contextualización histórica y social de todos y cada uno de los pasos del pintor, biográficos y artísticos. Su lectura, lejos de centrarse con exclusividad en un estilo y un catálogo, nos traslada al momento histórico, a otros personajes. A valorar la procedencia de iconografías, temas y hábitos sociales. En definitiva, un pintor que no fue "social», sino «sociable», exigía un estudio amplio en cuanto a sus límites conceptuales que nos ayudase, no solo a entender al artista, sino también a su época.

Francisco José Rodríguez Marín Universidad de Málaga 